\title{
Mapeamento da produção intelectual em periódicos científicos: estudo em uma Faculdade de Educação
}

\author{
Ana Gabriela Clipes Ferreira \\ Universidade Federal do Rio Grande do Sul, Faculdade de Educação, Porto Alegre, RS, Brasil \\ anaclipes@ufrgs.br
}

Clovis Milton Duval Wannmacher

Universidade Federal do Rio Grande do Sul, Instituto de Ciências Básicas da Saúde, Porto Alegre, RS,

Brasil

clovisdw@ufrgs.br

DOI: https://doi.org/10.26512/rici.v11.n3.2018.10435

Recebido/Recibido/Received: 2018-03-15

Aceitado/Aceptado/Accepted: 2018-06-19

Resumo: O presente artigo tem como objetivo geral analisar a produtividade da Faculdade de Educação (FACED) da Universidade Federal do Rio Grande do Sul em periódicos científicos. Pesquisa cientométrica, com abordagem de métodos quantitativo, exploratório e descritivo. Coleta de dados da produção intelectual da FACED inserida no Sistema de Bibliotecas da Universidade de 2000 a 2014, tratada em planilha eletrônica. Para contextualização dos dados, na primeira etapa é realizada a análise da produção em geral, com todos os tipos de documento, para o posterior aprofundamento e resposta do objetivo geral e específicos. A pesquisa aponta, entre diversos resultados, a maior produtividade em periódicos nacionais não indexados. Esse tipo de documento não seria recuperado em bases de dados tradicionais. Também indicou o crescimento da produção em periódicos científicos, possivelmente ligado ao crescimento da Pós-Graduação no país.

Palavras-Chave: Cientometria. Faculdade de Educação. Periódicos científicos. Produção científica.

Mapping intellectual production in scientific journals: study at a Faculty of education

Abstract: The main objective of the present article is to analyze the productivity of the Faculty of Education (FACED) of the Federal University of Rio Grande do Sul in scientific magazines. It is a scientometric investigation with an approach of quantitative, exploratory and descriptive methods. The collected data from FACED intellectual production, in the interval of 2000 to 2014, inserted in the System of Libraries of the University were treated in an electronic spreadsheet. To contextualize the data, the first step of the production analysis is carried out in general, with all types of documents, for further examination and then the answer of the general and specific objectives. The research points, between several results, to the major productivity in not indexed national magazines. This type of document would not be recovered in traditional databases. The research also indicated the growth of the production in scientific magazines, possibly connected to the growth of the Graduation in the country.

Keywords: Cientometrics. Faculty of Education. Scientific journals. Scientific production.

Mapa de la producción intelectual en periódicos científicos: estudio en una Facultad de Educación Resumen: El presente artículo tiene como objetivo general analizar la productividad de la Facultad de Educación (FACED) de la Universidad Federal de Rio Grande do Sul en periódicos científicos. Investigación cientométrica, con abordaje de método cuantitativo, exploratorio y descriptivo. Recolección de datos de la producción intelectual de la FACED, insertada en el Sistema de Bibliotecas de la Universidad de 2000 a 2014, tratada en hoja de cálculo. Para la contextualización de los datos, en la primera etapa se realiza el análisis de la producción en general, con todos los tipos de documentos, para la posterior profundización y respuesta del objetivo general y específicos. La encuesta apunta, entre 
diversos resultados, la mayor productividad en periódicos nacionales no indexados. Este tipo de documento no se recuperará en bases de datos tradicionales. El estudio también indicó el crecimiento de la producción en periódicos científicos, posiblemente ligado al crecimiento del Post-Graduación en el país.

Palabras clave: Cientometría. Facultad de Educación. Periódicos científicos. Producción científica.

\section{Produção científica}

Os pesquisadores das diferentes áreas do conhecimento possuem características e motivações próprias ao publicar seus resultados de pesquisa. Meadows (1999) apresenta o comportamento de publicação das áreas do conhecimento e aponta os principais veículos em que cada uma prefere publicar afirmando, por exemplo, que as ciências humanas preferem publicar em livros, enquanto as ciências médicas em periódicos científicos. Carvalho e Manoel (2006) corroboram ao afirmar que nas ciências sociais e humanas os livros ainda são tradicionalmente o meio de comunicação da produção destas áreas. Para Giménez-Toledo, Tejada-Artigas e Mañana-Rodríguez (2013), os livros possuem as características mais adequadas para comunicação dos resultados das pesquisas na área.

É possível observar, entretanto, que os paradigmas de publicação, produção e avaliação das ciências mudam rapidamente. Se antes o impacto e a presença em bases de dados eram um objetivo quase exclusivo da área das ciências duras, é possível observar atualmente a preocupação de outras áreas em possuir esse tipo de visibilidade perante a comunidade científica. Kuhn (1998) diz que a ciência normal tem como objetivo originar novas espécies de fenômenos, afirmando que aqueles que não se ajustam aos limites dos paradigmas frequentemente nem são vistos. No final do século XX e neste, observa-se que muitos são os paradigmas quebrados, mesmo nas áreas do conhecimento mais rigorosas. Esta ruptura dos modelos, mesmo de maneira mais ou menos sutil, proporciona que a ciência evolua e continue completando seu ciclo.

Pesquisar e publicar resultados são atividades quase conjuntas na comunicação científica. Um estudo não publicado, na visão de determinadas áreas, não existe. Meadows (1999) corrobora com tais afirmações, ao dizer que a comunicação é vital para a ciência, assim como a pesquisa. No cenário nacional, os Programas de Pós-Graduação (PPG) strictu sensu exigem pré-requisitos para a vinculação de docentes e, entre estes, há a publicações em periódicos. Através da produção realizada pela Pós-Graduação, as agências de fomento no Brasil, como a Coordenação de Aperfeiçoamento de Pessoal de Nível Superior (CAPES), avaliam os veículos de publicação, ou seja, os periódicos, atribuindo-lhes estratos através do Qualis na Plataforma Sucupira da CAPES. A CAPES também é responsável pela atribuição de notas aos PPG, analisando diversos critérios, entre eles a produtividade. A busca por qualidade, bem 
como mantê-la, é um objetivo em comum das publicações periódicas e dos programas de pós. Desta forma pode-se reafirmar que a publicação em periódicos possui forte ligação com a PósGraduação no Brasil, uma vez que estão entre os veículos utilizados para a avaliação dos programas.

Análises cientométricas em bases de dados nas quais estão indexados periódicos são frequentemente realizadas, objetivando, além de quantificar tais produções, apresentar resultados que possam auxiliar no progresso científico. A ciência é uma entidade mensurável, podendo sofrer aplicação de métodos quantitativos e, ao serem devidamente tratados esses números, são gerados dados que possibilitam apontar a trajetória das curvas de evolução da ciência (SOLLA PRICE, 1976). Os estudos cientométricos têm avançado na diversificação de temas e abordagens empregadas. O que era visto somente como estatística pura ganha uma nova dimensão com a análise qualitativa aliada aos resultados numéricos, ou seja, autores preocupados não somente em apresentar ou descrever uma situação, mas sim em entender o fenômeno que gerou tais resultados e suas implicações na academia e na sociedade. Os estudos cientométricos proporcionam o conhecimento da ciência de uma determinada comunidade científica através de sua produtividade. Estes podem analisar a produção de um país, de um conjunto de autores, entre outros resultados.

O termo cientometria foi inserido na década de 1960 por Vassily V. Nalimov. Desde então, tem sido usado para descrever os estudos ou mapeamento da ciência, como os relacionados ao crescimento, a estrutura e a produtividade científica. Os termos cientometria, bibliometria e informetria estão relacionados, pois utilizam métodos similares que podem ser aplicados em estudos com a finalidade de auxiliar no desenvolvimento de coleções de uma biblioteca, por exemplo, ou apresentar a produtividade de grupo de pesquisadores, de determinadas áreas do conhecimento, regiões ou países (HOOD; WILSON, 2001). No Brasil, o primeiro estudo cientométrico foi realizado em 1977: Morel e Morel analisaram a produção brasileira indexada no ISI e identificaram os autores mais citados, a produtividade e a distribuição por região, estado e instituição (MEIS; LETA, 1996.).

Desta forma, questiona-se quais as características das publicações em periódicos da comunidade científica da Faculdade de Educação da Universidade Federal do Rio Grande do Sul (FACED/UFRGS).

\section{Contextualização e objetivos do estudo}

Fundada em 1970, a Faculdade de Educação (FACED) possuía 129 docentes em março de 2016 divididos em 3 departamentos: 34 no Departamento de Estudos Básicos (EDU01), 48 no Departamento de Ensino e Currículo (EDU02) e 47 no Departamento de Estudos 
Especializados (EDU03). O Programa de Pós-Graduação em Educação, fundado em 1974, oferece os cursos de mestrado acadêmico e doutorado e possui 101 professores orientadores vinculados à UFRGS e outras instituições, além de professores convidados e outros colaboradores.

Os professores da FACED possuem formações acadêmicas diversas, tanto na área das humanidades quanto das ciências exatas. Há docentes com formação em Ciências Sociais, História, Geografia, Letras, Psicologia, Filosofia, Teatro, Matemática, Ciências Biológicas, Química, Informática, entre outras. Na descrição do site da FACED, no espaço reservado aos departamentos já é apontado que atendem a distintas graduações e "Em decorrência da grande diversidade desses cursos, a formação desses docentes é bastante variada." (UFRGS, 2015, documento não paginado). Porém, a grande área da FACED são as ciências humanas, subárea de educação.

Os docentes ligados aos departamentos são responsáveis diretamente pela formação dos discentes do curso de Licenciatura em Pedagogia, todavia, outros cursos de licenciatura possuem disciplinas obrigatórias na FACED. Assim sendo, pode-se afirmar que o prédio da Faculdade de Educação é o berço da formação de professores. Também oferece o curso de Pedagogia na modalidade à distância (PEAD), curso no qual o foco é qualificar professores que já estão em sala de aula, porém sem possuírem ensino superior. Com objetivo similar, qualificar professores já atuantes, o curso de Licenciatura em Educação do Campo: Ciências da Natureza, cuja primeira turma ingressou em 2014, possui caráter interdisciplinar. Ambos são cursos oferecidos por edições, que poderão, por ventura, possuir mais edições ou mesmo tornarem-se permanentes no quadro de graduações oferecidas pela universidade.

Por fim, os docentes, ao ingressarem na UFRGS e aos que desejam realizar um curso de educação continuada, é oferecido o Programa de Atividades de Aperfeiçoamento Pedagógico (PAAP). Organizado em conjunto com a Pró-Reitoria de Graduação, Faculdade de Educação e Secretaria de Educação à Distância é mais um exemplo do caráter multidisciplinar da FACED, bem como a forte presença na formação de professores em todos os níveis de aprendizado.

É inegável a importância da FACED na UFRGS e perante a sociedade. Portanto, apresentar estudo mapeando a ciência produzida por essa comunidade é relevante, tendo em vista que, além de possuir caráter multidisciplinar, apresenta áreas escassamente contempladas nos estudos métricos e em bases de dados internacionais, em especial as humanidades.

Das diversas áreas do conhecimento de formação dos docentes, algumas não possuem tradição em bases de dados, fator de impacto, tão pouco estão presentes na Web of Science 
(WoS) ou Scopus, ferramentas comumente utilizadas em estudos métricos. Assim, as ferramentas para aplicação da metodologia e a coleta de dados não são tão aprimoradas quanto as oferecidas para estudos tradicionais, em áreas do conhecimento também tradicionais nestes estudos métricos. Há uma certa urgência em realizar estudos em áreas e revistas não contempladas nessas bases. Mais ainda: em áreas do conhecimento de países cuja ciência está em desenvolvimento e que não adotam amplamente o idioma da ciência, ou seja, o inglês (VASCONCELOS; SORENSON; LETA, 2007).

Neste estudo, de caráter multidisciplinar, tratando de diferentes áreas sendo a educação predominante, os resultados poderiam ser recuperados em ferramentas tradicionais, ao tratar das ciências exatas, por exemplo, mas ao abordar as áreas das humanidades, ferramentas alternativas foram necessárias para apresentar resultados mais fiéis à produtividade do grupo estudado. Pizzani, Silva e Hayashi (2008) realizaram estudo verificando a presença da área de educação especial na base de dados Medline. Para as autoras, a educação especial interage com outras áreas do conhecimento através da produção científica em periódicos científicos nacionais e internacionais, indexados em bases de dados. Utilizaram a bibliometria como instrumento de análise para medir a atividade científica e foram analisados temáticas abordadas, autoria geográfica, idioma, ano de publicação, frequência de citação dos artigos e fator de impacto das fontes localizadas. Tal pesquisa foi possível pela interação da temática com a área de saúde, principal abordagem da Medline. Outras temáticas da educação possivelmente não seriam localizadas em tal base, impossibilitando um estudo como os objetivos desta pesquisa.

O objetivo desta pesquisa é analisar a produtividade dos docentes da Faculdade de Educação da Universidade Federal do Rio Grande do Sul em periódicos científicos entre 2000 e 2014. A seguir, verificar em quais títulos há o maior número de artigos e caracterizar essas publicações; identificar os pesquisadores com maior número de publicações no intervalo da pesquisa; identificar os títulos de periódicos mais frequentes, verificando também em quais fontes de informação estão presentes; verificar o tipo de acesso dos periódicos e das fontes de informação; por fim, tecer considerações acerca dos resultados com base na literatura científica.

\section{Procedimentos metodológicos}

Trata-se de pesquisa cientométrica, com adoção de métodos quantitativo, exploratório e descritivo. São descritos a seguir os procedimentos adotados. 


\subsection{Coleta dos dados}

Na UFRGS, as publicações dos docentes são catalogadas no Sistema de Automação de Bibliotecas (SABI), que utiliza o software Aleph (versão 20.1). A plataforma oferece campos do formato Machine Readable Cataloging (MARC) diferenciados no registro para identificar aquelas que são produção da instituição.

A produtividade registrada no catálogo é utilizada para fins de progressão funcional e distribuição de vagas docentes nos departamentos, cujo depósito é realizado nas bibliotecas setoriais das unidades (UNIVERSIDADE, 2006; UNIVERSIDADE, 2001; OLIVEIRA et al., 2004). 0 depósito da produção intelectual docente na UFRGS possibilita ainda preservação da memória institucional e acesso aos interessados nos resultados de pesquisa.

Os dados foram coletados através dos registros bibliográficos da produção intelectual dos docentes da FACED dos três departamentos (Ensino Básico - DEBAS, EDU01, Ensino e Currículo - DEC, EDU02 e Estudos Especializados - DEE, EDU03) e geral da Faculdade de Educação, que inclui os colaboradores, como professores aposentados e outros colaboradores permanentes ou temporários e técnico-administrativos (EDUO). Quando um registro possui dois autores de diferentes departamentos é listado mais de uma vez.

O corte temporal é de 2000 a 2014. O período foi escolhido devido a importantes mudanças no panorama da comunicação científica no Brasil, podendo ser citado o crescimento dos Programas de Pós-Graduação e a consolidação dos periódicos científicos eletrônicos através de iniciativas como o Portal de Periódicos da CAPES. Devido ao intervalo ser longo e para minimizar o tempo de coleta de dados, bem como possíveis falhas, foi solicitado, em junho de 2015, à Gerência do SABI planilha eletrônica em extensão xls com os principais dados de cada registro, entre eles: título, autores, departamento, ano e tipo de produção intelectual. Para esta análise, foram selecionadas as publicações em periódicos nacionais indexados e não indexados, internacionais, indexados e internacionais não indexados.

Optou-se pelo uso dos dados contidos no software Aleph com o intuito de mapear com maior precisão a produção de artigos que não seriam recuperados em bases de dados convencionalmente utilizadas em estudos cientométricos, seja pela abrangência de assunto ou idioma destas. Outra razão significativa é a presença expressiva de periódicos internacionais netas bases e, sendo assim, os títulos nacionais não seriam recuperados. Dessa forma, é possível que, mesmo com as limitações existentes em qualquer estudo de mapeamento da ciência, o resultado tenha maior proximidade com a realidade da produção do grupo selecionado para a pesquisa. Spinak (1998) destaca a importância da elaboração de métodos adequados para a formulação de indicadores científicos e, para esta pesquisa, portanto, o método adotado para a coleta de dados é adequado para atingir os objetivos. 
Nesta pesquisa, entre os limitadores possíveis ao optar por este método de coleta de dados, está a ausência de documentos não depositados pelo docente na respectiva biblioteca ou depósito tardio (muito tempo após a publicação), atraso ou demora na publicação do periódico (ao contrário do Currículo Lattes, onde é possível inserir artigos aceitos e pré prints, no catálogo de bibliotecas somente é aceito o formato final da publicação) e registros catalogados equivocadamente. Outra deficiência é a análise dos vínculos dos autores de diferentes instituições, que nas bases de dados tradicionais consta nos registros salvos, possibilitando análise de rede de autorias.

Entre as vantagens, como já foi citada, a maior abrangência de publicações periódicas, pode-se citar como um diferencial da coleta de dados no Aleph não ser necessário realizar a limpeza e padronização nos dados de nome dos autores devido ao controle de autoridades realizado no software, pouca probabilidade de existência de registros duplicados erroneamente, uma vez que são inseridos por profissionais bibliotecários com formação e treinamento adequados. Mugnaini (2006) apontou que grande parte do esforço despendido nas análises bibliométricas são justamente a padronização dos dados, tendo em vista que em muitos estudos os dados são coletados na Information Sciences Institute (ISI) e outras bases de dados bibliográficas nas quais é bastante marcante a falta de uniformidade. Mugnaini (2006, p. 100) ainda afirma que "o uso de referências bibliográficas para análises bibliométricas impõe a transformação de dados bibliográficos em dados bibliométricos. Desta forma, a padronização da informação é uma exigência, já que se deve garantir a homogeneidade das informações a serem compatibilizadas".

Café e Brascher (2008) dizem que as dificuldades encontradas na aplicação dos estudos bibliométricos são similares às dos sistemas de recuperação da informação, tendo em vista a descrição e recuperação de conteúdo. No estudo das autoras, foi constatado, através de entrevista com especialistas na área, que as bases de dados utilizadas como fonte de coletas de dados nas pesquisas bibliométricas geralmente não são planejadas para este fim, existindo assim dificuldade na coleta e padronização dos dados.

$\mathrm{Na}$ planilha elaborada para a coleta de dados constam todos os autores. Assim, documentos que contivessem et al. para indicação de quatro autores ou mais, onde o docente não fosse o primeiro autor, em outras bases de dados poderia não ser recuperado. Estas omissões de nomes de coautores atingem diretamente nos estudos quantitativos (CAFÉ; BRASCHER, 2008).

Por fim, aponta-se como outra vantagem da coleta de dados a partir dos registros bibliográficos do Aleph a vinculação do autor com a Universidade: somente documentos com 
data a partir do vínculo do autor como docente serão inseridos os campos 090 e 909 no registro, considerando-se assim como produção intelectual UFRGS.

\subsection{Tratamento dos dados}

A análise quantitativa dos dados foi realizada do recurso tabela dinâmica da planilha eletrônica. Foram quantificados os números totais de artigos publicados no intervalo (20002014). Glänzel (2003) dividiu os indicadores métricos em três: indicadores de atividade, indicadores de citação e indicadores de colaboração. Dessa forma, indicadores de atividade são utilizados nesta pesquisa, uma vez que são elaborados a partir da contagem do número de publicações de um determinado autor, área do conhecimento, disciplina, país, região e instituição, além de permitir análises de desempenho e caracterização destes.

São identificados os títulos de periódicos que possuem maior número de artigos do grupo de docentes. Após essa identificação, foi realizada breve descrição da publicação: título, área do conhecimento da publicação, idioma, editor, tipo de acesso e estrato Qualis. Por fim, foram identificados os autores com o maior número de publicações dentro do período e observado quais desses professores possuem vínculo com o Pós-Graduação. Foi apontado o professor com maior número de artigos publicados entre 2000 e 2014. Desta forma, no quadro com os dados serão indicados o início e o final do vínculo como docente na Universidade, e a média de artigos publicados durante este período. Também foi identificado se há vínculo com Programa de Pós-Graduação. Identifica-se, por fim, a taxa total de crescimento, através da fórmula simples de taxa de crescimento, que é o (valor final-valor inicial)/valor inicial.

\section{Resultados}

Entre os anos de 2000 e 2014 foram inseridos pela Biblioteca Setorial de Educação 13.742 registros referentes a produção intelectual da FACED entre todos os tipos de documento. Novamente os trabalhos em eventos nacionais estão em maior número, se comparado com o Censo 2010 do Diretório de Grupo de Pesquisas CNPQ, o último a ser realizado pelo CNPQ: após o plano tabular foi descontinuado (CNPQ, 2016). Os capítulos de livros surgem como o segundo tipo de documento mais frequente, seguido dos trabalhos que envolvem orientação: trabalho de conclusão de curso de graduação, dissertação de mestrado e trabalho de conclusão de curso de especialização.

A soma dos livros e capítulos de livros é de 18,3\% ou 2517 registros: os artigos periódicos somam 1.431 do total de registros, representando, portanto, cerca de 10,5\% do total de documentos do recorte temporal. O sexto tipo de documento onde há maior ocorrência consiste nos artigos publicados em periódicos nacionais. 
Após organizar os dados referentes às publicações periódicas, quais sejam, artigos publicados em periódicos nacionais indexados e não indexados, estrangeiros indexados e estrangeiros não indexados, houve a verificação e padronização dos dados. Foram uniformizados os títulos dos periódicos. Alguns equívocos na catalogação, como a descrição do mesmo título de duas ou mais formas foram observados. Ainda assim, além dos dados terem sido extraídos do catálogo da biblioteca, o número de registro possibilitou a revisão e apontou ainda a necessidade de correção de registros no software Aleph. A Tabela 1 identifica os tipos de periódicos, indicando que no intervalo de tempo selecionado para a pesquisa o tipo de revista onde mais os docentes publicaram foram os nacionais indexados.

Tabela 1- Publicação por tipo de periódico de 2000 a 2014

\begin{tabular}{|c|c|c|}
\hline Tipo de periódico & Frequência & Porcentagem (\%) \\
\hline Indexado nacional & 832 & 58,1 \\
\hline Não indexado nacional & 427 & 29,9 \\
\hline Indexado estrangeiro & 90 & 6,3 \\
\hline Não indexado estrangeiro & 82 & 5,7 \\
\hline Total & 1431 & 100 \\
\hline
\end{tabular}

Fonte: os autores.

Neste caso, é possível afirmar que os autores preferem a via regional, como explicado por Meneghini (2012), ou seja, existe uma tendência por publicar em periódicos nacionais. Observou-se também que o crescimento das publicações periódicas nos anos de 2012 e 2013 (Figura 1) foi mais acentuado nos periódicos nacionais indexados. Em 2014 não é observado o mesmo crescimento, fato que é possivelmente explicado por dois principais motivos: atraso das publicações brasileiras e o artigo não ter sido depositado na biblioteca pelos docentes, uma vez que na época da coleta não havia sido encerrado o interstício da progressão funcional, que ocorre a cada dois anos.

A taxa de crescimento total desta amostra, aplicando a fórmula (valor final-valor inicial)/valor inicial foi de 0,54\%. Para Meadows (1999) a taxa de crescimento da informação aumentou de forma mais rápido do que o crescimento da respectiva comunidade científica na segunda metade do século XX. O autor exemplifica com a situação dos periódicos médicos nos Estados Unidos: entre 1960 e 1975, o número de títulos praticamente dobrou. Atualmente, é 
possível verificar esse aumento em diversas áreas. Porém, é preciso cautela ao afirmar números sobre o crescimento da produção científica no Brasil: em muitos casos, os números não são referentes ao aumento da produção, mas sim da indexação em bases de dados, conforme o exposto por Meneghini (2009), ao rebater pesquisas sobre o crescimento da produção brasileira em veículos de informação.

Figura 1-Número de artigos publicados em periódicos por ano

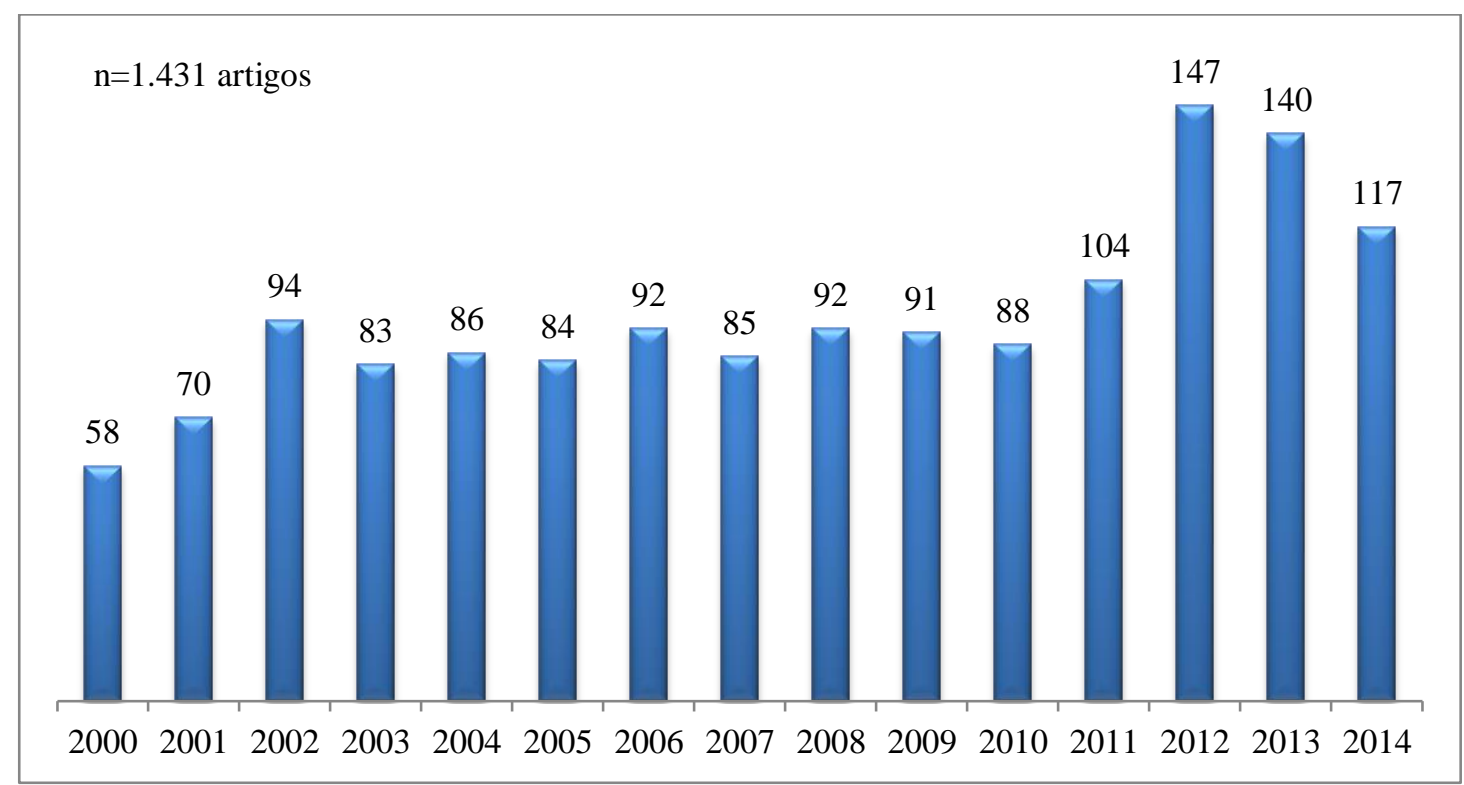

Vinkler (2010) diz que o crescimento da ciência é descrito na cientometria através de modelos baseados no crescimento cumulativo das publicações. O autor apresenta três modelos: o linear, o exponencial e o logístico. No linear, há um crescimento constante no número de artigos; no exponencial, há um rápido aumento após um período inicial; e no logístico, o crescimento é lento durante um período inicial, seguido de um aumento rápido e linear das publicações. Assim, Vinkler (2010) destaca que o aumento ou a diminuição do número de publicações por ano depende de diversos fatores, dentro e fora da ciência e os modelos apresentados podem ser válidos apenas para um período estudado, não tendo poder preditivo para períodos mais longos. Na seção seguinte, tratando da produtividade dos autores e dos departamentos, é possível identificar alguns dos motivos que podem ter impulsionado o aumento da produção em periódicos. 


\subsection{Produtividade por departamentos e por autores}

Na primeira análise da seção, é verificada a produtividade por departamento, contendo os dados por tipo de publicação e o número total de publicação também por tipo e a soma de todos.

O maior número de artigos de periódicos de todos os tipos está presente no Departamento de Estudos Especiais: 490 artigos. A seguir, o Departamento de Ensino e Currículo apresenta a segunda maior soma de documentos (428 artigos). O Departamento de Estudos Básicos apresentou 280 artigos e os docentes e colaboradores da Faculdade somam 233 artigos. Este resultado é proporcional ao número de professores que pertence a cada um dos três departamentos, porém o número de artigos de colaboradores não tem um parâmetro para comparação: o código EDUO é aquele designado a docentes aposentados com o vínculo na graduação encerrado e ingressante como professor convidado do PPG, bem como para técnicos-administrativos e outros profissionais com vínculo temporário à Faculdade de Educação.

Quadro 1 - Artigos publicados por departamento

\begin{tabular}{|c|c|c|c|c|c|}
\hline \multirow[b]{2}{*}{ Departamento } & \multicolumn{2}{|c|}{ Periódico indexado } & \multicolumn{2}{|c|}{ Periódico não indexado } & \multirow[b]{2}{*}{ Total } \\
\hline & Internacional & nacional & Internacional & nacional & \\
\hline $\begin{array}{l}\text { Faculdade de Educação } \\
\text { (EDU0) }\end{array}$ & 9 & 145 & 31 & 48 & 233 \\
\hline Estudos Básicos (EDU01) & 15 & 156 & 13 & 95 & 280 \\
\hline Ensino e Currículo (EDU02) & 33 & 230 & 16 & 149 & 428 \\
\hline Estudos Especiais (EDU03) & 33 & 300 & 22 & 135 & 490 \\
\hline Total & 90 & 832 & 82 & 427 & 1431 \\
\hline
\end{tabular}

Ao listar o número de produção por autor, o catálogo de autoridades demonstrou-se bastante consistente, tendo em vista que não foram necessários ajustes e revisões destes dados. Foram listados os autores mais produtivos com 20 artigos ou mais, organizados no Quadro 2, que também aponta o departamento do docente, vínculo com Programa de PósGraduação e datas de vínculo como docente na UFRGS. 
A autoria única está presente em 565 registros, 432 registros com dois autores, 173 registros com 3 autores. Com 4 ou mais autores, somam 127 registros, sendo: 0 maior número de autores acontece em dois registros com 11 autores, 5 registros com 10 autores, 8 registros com 9 autores, 10 registros com 8 autores, 17 registros com 7 autores, 29 registros com 6 autores, 58 registros com 5 autores e 117 registros com 4 registros. Para Meadows (1999) os artigos com múltiplas autorias dificultam a definição da produtividade de cada um deles. 0 autor demonstra, através de tabelas, que a autoria múltipla nas ciências dita duras é mais frequente, enquanto nas ciências sociais e nas humanidades é mais comum artigos com número menor de autores, sendo mais frequente autorias únicas, ou seja, menor colaboração científica entre os autores. Nederhof (2006) corrobora com Meadows sobre a cooperação na área das humanidades e Santos (2010) também observa nos resultados do seu trabalho resultado similar quanto as autorias na área das humanidades e ciências sociais em periódicos.

Quadro 2 - Autores com maior número de publicações em periódicos científicos, de 2000 a 2014.

\begin{tabular}{|l|c|c|l|c|c|}
\hline Docente & $\begin{array}{c}\text { No. de } \\
\text { artigos }\end{array}$ & $\begin{array}{c}\text { Departamento } \\
\text { ou Vínculo }\end{array}$ & $\begin{array}{c}\text { Período e tempo de } \\
\text { vínculo com a UFRGS }\end{array}$ & $\begin{array}{c}\text { Pós- } \\
\text { Graduação }\end{array}$ & $\begin{array}{c}\text { Média de Artigos } \\
\text { por ano*** }\end{array}$ \\
\hline Docente 1 & 59 & EDU03 & PPGEDU & PPGIE & 3,47 \\
\hline Docente 2 & 45 & EDU03 & 1998 -atual =17 anos & PPGEDU & 1,32 \\
\hline Docente 3 & 44 & EDU03 & 2007-atual=8 anos & PPGIE & 5,5 \\
\hline Docente 4 & 42 & EDU03 & 1997 -atual=18 anos & PPGEDU & 2,33 \\
\hline Docente 5 & 40 & EDU01 & 1994 -atual=21 anos & Não & 1,90 \\
\hline Docente 6 & 33 & EDU02 & 1994 -atual=21 anos & PPGEDU & 1,57 \\
\hline Docente 7 & 33 & EDU03 & 1990 -atual=25 anos & PPGEDU & 1,32 \\
\hline & 33 & EDU03 & 1969 -1997 & PPGIE & 0,71 \\
\hline Docente 8 & & EDU0 & 1997 -atual=46 anos & & 1,68 \\
\hline Docente 9 & 32 & EDU02 & 1996 -atual=19 anos & PPGEDU & 3,44 \\
\hline Docente 10 & 31 & EDU02 & 2006 -atual=9 anos & PPGEDU & \\
\hline
\end{tabular}




\begin{tabular}{|c|c|c|c|c|c|}
\hline Docente 11 & 29 & EDU01 & 1994-atual= 21 anos & PPGEDU & 1,38 \\
\hline Docente 12 & 29 & EDU03 & 2008-atual=7 anos & PPGIE & 4,14 \\
\hline Docente 13 & 27 & EDU02 & 1994-atual=21 anos & PPGEDU & 1,28 \\
\hline Docente 14 & 26 & EDU03 & $1995-2015=20$ anos & $\begin{array}{l}\text { PPGEDU } \\
\text { PPGIE }\end{array}$ & 1,3 \\
\hline Docente 15 & 26 & EDU02 & 1996-atual=19 anos & PPGEDU & 1,36 \\
\hline Docente 16 & 26 & EDU03 & 2001-atual=14 anos & PPGEDU & 1,85 \\
\hline Docente 17 & 23 & $\begin{array}{l}\text { EDUO2 } \\
\text { EDUO }\end{array}$ & $\begin{array}{l}1980-1995 \\
1995-2015=35 \text { anos }\end{array}$ & PPGEDU & 0,65 \\
\hline Docente 18 & 22 & $\begin{array}{l}\text { EDUO2 } \\
\text { EDUO }\end{array}$ & $\begin{array}{l}1997-1998 \\
1998-2018^{* *}=18 \text { anos }\end{array}$ & PPGEDU & 1,22 \\
\hline Docente 19 & 21 & $\begin{array}{l}\text { EDUO3 } \\
\text { EDUO }\end{array}$ & $\begin{array}{l}1967-1996 \\
2000-2016=34 \text { anos }\end{array}$ & $\begin{array}{l}\text { PPGEDU } \\
\text { PPGIE }\end{array}$ & 0,61 \\
\hline Docente 20 & 20 & EDU03 & 1993-atual=22 anos & PPGEDU & 0,90 \\
\hline Docente 21 & 20 & $\begin{array}{l}\text { EDUO2 } \\
\text { EDUO }\end{array}$ & $\begin{array}{l}1985-1998 \\
1999-2015=29 \text { anos }\end{array}$ & PPGEDU & 0,68 \\
\hline Docente 22 & 20 & EDU03 & 1995-atual=20 anos & PPGEDU & 1 \\
\hline Docente 23 & 20 & EDU02 & 2006-atual=9 anos & $\begin{array}{c}\text { PPGEDU (até } \\
\text { 2014) }\end{array}$ & 2,22 \\
\hline Docente 24 & 20 & $\begin{array}{l}\text { EDU01 } \\
\text { EDU0 }\end{array}$ & $\begin{array}{l}1998-2012 \\
2014-2015=15 \text { anos }\end{array}$ & PPGEDU & 1,33 \\
\hline
\end{tabular}

EDU 0= Faculdade de Educação; EDU 01= Estudos Básicos; EDU 02= Ensino e Currículo; EDU $03=$ Estudos Especiais.

* dados de setembro de 2015 e disponíveis no Módulo de Serviços SABI, Catalogação, Consulta Vínculo com a UFRGS.

** Professor/colaborador convidado, previsão de término do vínculo.

*** Considerado até 2015 , data de coleta de dados 
Dos 20 docentes da listagem, 7 deles são professores aposentados com vínculo de colaboradores no Programa de Pós-Graduação. O ingresso desses docentes é a partir de 1969 e o mais recente 2008, porém a maioria ingressou na UFRGS a partir da década de 1990 , sendo alguns a partir dos anos 2000. O tempo médio de vínculo de 20,91 anos. O gênero predominante é o feminino, sendo 13 autoras e 7 autores. Com exceção do(a) Docente 5, todos são orientadores de mestrado e/ou doutorado no Programa de Pós-Graduação em Educação e/ou Programa de Pós-Graduação em Informática da Educação (oferece apenas curso de doutorado) até a data final dos documentos da coleta de dados (2014). Houve um descredenciamento ou desligamento do Programa de Pós-Graduação, do Docente 23, em 2014. A média de artigos por ano foi de 1,22. A maior média de artigos ocorreu no Docente 3 , 5,5 artigos por ano e durante os 8 anos de vínculo na Universidade, e a menor foi 0,61 , do Docente 19.

Entre os requisitos para o docente possuir credenciamento (ingresso e permanência) ${ }^{1}$ com o PPGEDU, está a produção de artigos em periódicos científicos. Os resultados dos autores mais produtivos apontam para esta exigência: para orientação de mestrado, é necessário publicar três artigos em periódicos com estratos entre A1 e B5 (o estrato C é considerado inexpressivo), sendo pelo menos dois desses artigos em revistas com estratos entre $A 1$ e $B 2$ ou dois artigos, sendo um entre $A 1$ e $B 1$ e o outro $A 1$ e $B 5$ ou capítulo de livro ou livro. Para orientador de mestrado e doutorado, o número de artigos aumenta para seis, sendo que três artigos precisam estar presentes em revistas com estrato entre A1 e B2 ou4 artigos, sendo 3 deles em revistas com estrato entre A1 e B1 e um entre A1 e B5. Os capítulos de livros ou autoria de livros, tanto para orientação de mestrado, devem conter os níveis L4 ou L3, os estratos superiores do roteiro de avaliação de livros da CAPES. Outro item indicado é a participação em eventos internacionais.

Para alunos de mestrado e doutorado também é necessário que exista uma publicação em artigos de periódico, capítulo de livro ou artigo de evento, preferencialmente em coautoria com o orientador. No caso dos artigos de periódicos, é indicado inclusive o estrato Qualis da revista na área de educação ou correlata, sendo que, quando estrato $\mathrm{A} 1$ ou $\mathrm{A2}$ é necessário um artigo e estrato B1 a B5, dois artigos publicados ou aceitos para o mestrado e doutorado. ${ }^{2}$

Para Meadows (1999) os autores altamente produtivos são considerados bemsucedidos, ganhando promoção de cargo, que, consequentemente irá gerar mais atribuições e poderá interferir negativamente na sua produtividade. Por outro lado, esse mesmo pesquisador terá maior acesso a financiamentos e outros auxílios na pesquisa, que poderá

\footnotetext{
${ }^{1} \mathrm{http}: / /$ www.ufrgs.br/ppgedu/Resolucao_01_2013.pdf

2 http://www.ufrgs.br/ppgedu/arquivos/Resolucao_01_2015_regulamenta_publicacoes.pdf
} 
contribuir de maneira positiva. Para o autor, o pessoal universitário deve se envolver com ensino, administração e ainda pesquisa. Esse é um quadro bastante real das IES brasileiras.

O Departamento de Estudos Especializados (DEE) mais produtivo também é o que possui maior número de autores entre os que possuem maior número de publicações. O DEE “[...] é constituído pelas áreas de Política e Administração da Educação, Educação Infantil, Educação de Jovens e Adultos, Psicopedagogia e Tecnologia em Educação ${ }^{3}$." A última temática citada na descrição do departamento, tecnologia da educação, é bem representado nos títulos mais frequentes, como pode ser visto na seção seguinte.

\subsection{Títulos mais frequentes}

Após a organização e padronização dos títulos de periódicos, foram identificadas 289 diferentes revistas. Há um significativo número de títulos que possuem apenas uma ocorrência de artigo: 132 periódicos. Foram listados os periódicos que possuem pelo menos 10 ocorrências nesta amostra (Quadro 3), ou seja, 25 diferentes títulos. Destes, apenas dois não são brasileiros, mas também de língua portuguesa: uma de Braga e outra de Porto, ambas em Portugal. Entre os títulos n acionais, as regiões Sul e Sudeste possuem destaque. Dentre os periódicos brasileiros, as regiões Sul e Sudeste, nesta ordem, são predominantes.

Um viés da coleta foi constatado através de dois títulos, Pátio: revista pedagógica e Pátio: educação Infantil. Em outras áreas não é considerada uma revista científica, mas sim de divulgação científica e nesta coleta foi considerada um periódico não indexado. A revista é de responsabilidade de uma editora comercial e possui artigos direcionados principalmente aos professores e a prática escolar em sala de aula, assim como resenhas de livros, práticas para a sala de aula, entre outras sessões. Esse resultado interferiu nos autores mais produtivos: o(a) docente que não possui vínculo no programa de pós-graduação publica nesta revista ativamente.

No momento da escolha de tipo de produção intelectual, houve a decisão por tipo de documento por coleção da biblioteca, não pelo conteúdo. Verifica-se aqui a indicação de que a prática profissional bibliotecária está distanciada da teoria científica e das métricas em si, tornando-se demasiadamente técnica ao determinar o documento pelo formato que é disponibilizado em detrimento ao conteúdo dos artigos. Outro questionamento é sobre a pontuação no momento da avaliação e da progressão: se fora consolidado como artigo de periódico e não de divulgação. Entendemos então que, por ser uma inserção em uma base de

\footnotetext{
${ }^{3}$ http://www.ufrgs.br/faced/
} 
dados tão próxima institucionalmente dos pesquisadores, a definição da tipologia documental pode sofrer influência destes, mesmo com a existência de normativas sobre o tema.

Quadro 3 - Títulos mais frequentes

\begin{tabular}{|l|c|}
\hline \multicolumn{1}{|c|}{ Título } & N.o ocorrências \\
\hline Educação \& realidade. Porto Alegre, RS & 80 \\
\hline RENOTE: revista novas tecnologias na educação. Porto Alegre, RS & 65 \\
\hline Informática na educação: teoria \& prática. Porto Alegre & 52 \\
\hline Pátio: revista pedagógica. Porto Alegre, RS & 28 \\
\hline Educação (Porto Alegre). Porto Alegre, RS & 26 \\
\hline Pátio: educação infantil. Porto Alegre, RS & 26 \\
\hline A página da educação. Porto, Portugal & 18 \\
\hline Educação (São Paulo). São Paulo, SP & 18 \\
\hline Educação e sociedade. Campinas, SP & 17 \\
\hline Educação em revista (Belo Horizonte). Belo Horizonte, MG & 17 \\
\hline Educar em revista. Curitiba, PR & 15 \\
\hline Educação UNISINOS. São Leopoldo, RS & 14 \\
\hline Revista brasileira de educação. Belo Horizonte, MG & 14 \\
\hline Ciências \& letras (Porto Alegre). Porto Alegre, RS & 13 \\
\hline Revista brasileira de política e administração da educação. Porto Alegre, RS & 13 \\
\hline Educação (Santa Maria). Santa Maria, RS & 13 \\
\hline Cadernos da aplicação. Porto Alegre, RS & 13 \\
\hline Reflexão e ação. Santa Cruz do Sul, RS & 12 \\
\hline Revista do professor (Porto Alegre). Porto Alegre, RS & 12 \\
\hline Currículo sem fronteiras: revista para uma educação crítica e emancipatória. & 12 \\
\hline História da educação. Pelotas, RS & 11 \\
\hline Cadernos de educação (Pelotas). Pelotas, RS & 11 \\
\hline Espaço pedagógico. Passo Fundo, RS & 11 \\
\hline Educação em revista (Porto Alegre). Porto Alegre, RS & 10 \\
\hline Revista educação especial. Santa Maria, RS & 10 \\
\hline
\end{tabular}

O título onde mais constam artigos de autoria de docentes da FACED é a revista Educação \& Realidade (E\&R), com 80 ocorrências. É uma publicação de acesso aberto, nos formatos impresso e eletrônico, editada pela própria Faculdade, criada em 1976, de periodicidade trimestral desde 2013, possui artigos e resenhas em português e inglês. Atualmente, a revista possui estrato Qualis A1 em Educação. Entre as principais fontes de informação constam: Scientific Electronic Library Online (SciELO), Educa: Periódicos online de Educação, Bibliografia Brasileira em Educação INEP/MEC, Fundação Carlos Chagas, Citas Latino americanas en Sociologia, Economia y Humanidades (CLASE), Red de Revistas Científicas de América Latina y el Caribe, España y Portugal (Redalyc), Índice de Revistas en Educación Superior y Investigación Educativa (IRESIE), Latin American Periodicals Tables of Contents (LAPTOC) e Sistema Regional de Información en Línea para Revistas Científicas de América 
Latina, el Caribe, España y Portugal, Directory of Open Access Journals (DOAJ), além do Portal de Periódicos da CAPES.

A revista RENOTE é o segundo título com maior número de ocorrências: 65 registros. É uma publicação interdisciplinar, semestral (com dois números regulares e eventualmente um terceiro fascículo especial), de acesso aberto e exclusivamente em meio eletrônico também editada pela UFRGS, Centro Interdisciplinar de Novas Tecnologias da Educação (CINTED). Tem como objetivo publicar artigos sobre o uso de tecnologias de comunicação e informação na educação. Publica em português, inglês e espanhol. Está presente no Portal de Periódicos da CAPES, DOAJ e Latindex, entre outras fontes. O primeiro volume data de 2003. O estrato Qualis em educação é B4.

O periódico Informática na Educação possui 53 ocorrências. É uma publicação interdisciplinar do Programa em Informática da Educação, CINTED/UFRGS, com início das publicações semestrais desde 1998. Possui Qualis B3 em educação, de acesso aberto, foi concebida em formato impresso e eletrônico, disponibilizada apenas em formato online desde 2012. Publica em português, inglês e francês. Está presente no LAPTOC, LATINDEX, Sumários.org e Portal do conhecimento Nuclear (LivRe!).

Os três primeiros títulos com maior número de ocorrências são periódicos editados pela própria UFRGS, tendo em comum também o uso do Sistema Eletrônico de Editoração de Revistas (SEER). Todos possuem acesso aberto, um dos itens promotores de visibilidade, conforme Packer e Meneghini (2006). As fontes de informação são, analisando o grupo, regionais e multidisciplinares. A maioria publica artigos predominantemente em língua portuguesa.

A revista Educação \& Realidade (E\&R) é uma publicação consolidada, possui mais de 40 anos e o escopo editorial é bem definido na área de educação. Possui indexação relevante nacionalmente e estrato Qualis máximo na área. Os dois títulos seguintes possuem caráter interdisciplinar, porém com especial destaque para a área de informática na educação e ambas são editadas no mesmo centro. Não possuem o mesmo prestígio acadêmico da $E \& R$, tanto em indexação como a avaliação do Qualis, contudo, não possuem o mesmo tempo de edição.

A E\&R possui temática distinta das outras duas revistas, que publicam artigos voltados a área de informática na educação e são interdisciplinares, além de serem editadas pelo mesmo centro. Zanotto et. al (2013) analisaram as citações no Google Acadêmico de dois periódicos da UFRGS, em Questão e Intexto, editados pela Faculdade de Biblioteconomia e Comunicação (FABICO). As autoras constataram que ambas as revistas possuíam visibilidade similar e abordavam a mesma temática: Informação e Comunicação. Sugerem que os periódicos integrem esforços para aumentar o alcance. Em 2014, as duas publicações 
realizaram mudança editorial: enquanto a revista Em Questão ${ }^{4}$ publica artigos da área de ciência da informação e áreas afins, a Intexto ${ }^{5}$ foca em artigos da área de comunicação. Para os dois periódicos editados pela CINTED, tanto o exemplo das revistas da FABICO como do estudo de citações do Google Acadêmico é uma possibilidade de fortalecimento das publicações na área do seu escopo editorial.

Sendo uma das funções dos periódicos científicos a divulgação da produção científica, foram criadas revistas, em especial as editadas nas instituições de ensino superior (IES) com o intuito de disseminar a produção local. Para Meneghini (2012), no Brasil e em países emergentes, os periódicos científicos não possuem caráter comercial como nos países desenvolvidos, mas sim atender as demandas da produção científica dos países. Além disso, são financiadas de maneira significativa pelo poder público.

A publicação de artigos de autores locais na revista não repercute bem na comunidade cientifica, pois, a avaliação pelas agências de fomento e bases de dados indicará caráter de ciência endógena e apontará essa característica como negativa. A endogenia de autores e comitê editorial em uma revista não é considerada uma boa prática, uma vez que a visão unilateral quando os autores, avaliadores e comitê são de uma mesma instituição compromete o desenvolvimento científico (VALÉRIO, 1994; COSTA, 2006). Não é adequado afirmar que as três revistas são endógenas, uma vez que não foi analisado o conteúdo geral do periódico, tal como realizado pelas agências de fomento e bases de dados, somente os veículos de comunicação nos quais publicam autores da instituição. Todavia, os autores possuem características de produtividade regionalizada, uma vez que as publicações em maior número são em revistas da própria instituição, como apresentado nos resultados. Foi uma característica marcante no recorte temporal desta pesquisa e para uma possível mudança neste cenário somente com observação e coleta de dados futuras. Acredita-se que, com as políticas editoriais dos periódicos cada vez mais rigorosas, tanto na endogenia institucional, como regional e o compromisso assumido em se tornar internacionalizadas, em médio prazo a produção possa ser mais diversa, seja nacional ou internacional, porém respeitando as características da área do conhecimento e consequentemente dos pesquisadores e a comunidade na qual estão inseridos.

Forattini $(1996$, p. 8) traz seu ponto de vista sobre a endogenia. Para o autor, a ciência endógena:

Em contrapartida à anterior, esta vem a ser a motivada pela necessidade de encontrar soluções para problemas de caráter

\footnotetext{
${ }^{4}$ http://seer.ufrgs.br/EmQuestao

${ }^{5}$ http://www.seer.ufrgs.br/intexto
} 
predominantemente nacional. Claro está que esse tipo de estudo, ao menos sob o ponto de vista teórico, interessará precipuamente à população do país onde é realizado, na medida em que lhe propiciará a melhoria da qualidade de vida. Uma vez que a motivação é nacional, no caso dos países terceiro-mundistas, em geral essa atividade científica deixa de se traduzir em "rentabilidade", no sentido de objetivar o desenvolvimento de tecnologia passível de comercialização. Essa baixa atratividade acaba repercutindo na divulgação dos resultados, a qual vai se restringir ao âmbito do país de origem ou ao dos que thes são semelhantes e se vêem a braços com problemas análogos.

O autor segue fazendo diversas considerações sobre o assunto e sugere que as revistas com caráter endógeno não possuem critérios que possibilitem a indexação no ISI, por exemplo, e consequentemente não alcançam visibilidade. Fica claro no decorrer do texto que Forattini (1996) defende a ciência endógena, sem desmerecer as vantagens apontadas pela ciência exógena, tendo em vista a contribuição local das publicações. Salienta-se que o caráter endógeno que o autor discorre é regional, não institucional.

É possível que pareça contraditório abordar o ponto de vista de um pesquisador que defende a endogenia quando o cenário atual da ciência brasileira é rumar para a internacionalização. Cabe uma reflexão sobre os temas de interesse local e público que atinge: certamente o público alvo é bastante específico, porém a publicação em revistas internacionais não traria maior repercussão? Não seria possível a outros países com problemas semelhantes, independente da área do conhecimento (saúde, educação, entre outros) beneficiar-se dos resultados? Em matéria sobre a escolha da revista mais adequada para se obter maior impacto (ANDRADE, 2016), há trechos de entrevistas com pesquisadores e estes afirmam que o mais adequado é publicar em revistas onde se encontrem artigos que são úteis e que preferem publicar em uma revista da própria da área invés de uma que possua maior fator de impacto. Possivelmente essa lógica possa ajudar a entender os motivos da endogenia nos títulos de maior número de publicações da população da FACED: são revistas específicas de uma área que até pouco tempo não possuía tradição em indexação e o fator de impacto não é relevante nas avaliações como ocorre em outras áreas do conhecimento.

Destaca-se mais uma vez a importância do acesso aberto das publicações científicas e os benefícios proporcionados à ciência. As bases de dados convencionais não permitem acesso gratuito à comunidade em geral, sendo seu acesso normalmente realizado através de assinaturas institucionais, enquanto o acesso aberto não possui tal limitação. Evans e Reimer (2009) afirmam que o acesso aberto estimula a participação global da ciência e podem possibilitar aumento do número de citações.

Os autores levam em conta o prestígio, geralmente ligado à tradição e idade da revista, e a circulação, relacionada ao prestígio do periódico ao fazer a escolha do veículo onde 
pretendem publicar seus resultados (MEADOWS, 1999). O prestígio e a circulação estão relacionados também à visibilidade, como a indexação em bases de dados e fator de impacto. No Brasil, outro fator considerado é a avaliação Qualis da CAPES. Frigeri e Monteiro (2014) realizaram trabalho procurando compreender a forma como o Qualis participa da rotina editorial dos periódicos nacionais. A pesquisa realizou entrevista e estudo etnográfico com editores da área de educação. Os autores verificaram que o Qualis, como indicador científico, possibilita a construção de um conceito de qualidade orientador e atuante na maneira como as publicações funcionam. Porém, é controversa entre a comunidade científica brasileira a consolidação do Qualis como indicador científico, uma vez que há preocupação com a definição de ciência de qualidade.

Processos de avaliação são subjetivos e passíveis de críticas e, com o Qualis, não é diferente. Embora existam critérios de avaliação para cada área do conhecimento, esses nem sempre são claros aos editores e autores. Costa (2006) verificou a divergência entre os autores envolvidos nas comissões do Qualis: para parte deles, o modelo é inadequado para representar a realidade editorial da área, além de discordarem em relação aos critérios adotados. Para a autora, a qualidade do conteúdo da revista deveria ser medida através dos artigos. Ainda assim, na área analisada, os instrumentos de avaliação do Qualis, continuam garantindo um padrão mínimo de qualidade das publicações.

Dentro da academia, os pesquisadores são avaliados de maneira quantitativa em determinados requisitos, citando como exemplo a própria política de inserção da produção intelectual nas bibliotecas com fins de progressão funcional e alocação de vagas docentes como as exigências para docentes e discentes dentro dos Programas de Pós-Graduação. Para Vanz e Stumpf (2010) a avaliação quantitativa é uma tendência mundial uma vez que é um recurso essencial para a formação de indicadores, podendo definir estratégias regionais e institucionais, servindo também para a avaliação dos resultados das políticas implementadas.

Nesta pesquisa, um dos resultados aponta que os docentes mais produtivos orientam no Programa de Pós-Graduação da Faculdade. Tanto para professores orientadores como para alunos, comumente existe a necessidade de publicação durante a realização de Pós-Graduação stricto sensu e estes são avaliados através dos seus veículos de comunicação, quais sejam, os periódicos científicos.

\section{Considerações finais}

Os periódicos nacionais atingem ao público alvo tendo em vista que as temáticas abordadas em determinadas áreas da educação são de interesse nacional, como determinados programas ou políticas educacionais. Outrossim, dividir as experiências brasileiras ou mesmo 
compará-las à realidade de outros países, pode gerar interesse e debates em revistas internacionais. Dessa forma, sugere-se ampliação do alcance da produção da FACED, atualmente regional quando analisados os artigos em periódicos.

Neste estudo, especificamente, pode-se inferir que o prestígio e a circulação da revista são considerados na escolha do veículo de comunicação científica. O título mais frequente entre os docentes autores da FACED é um periódico bem qualificado dentro da área do conhecimento e, por conseguinte, perante os órgãos que avaliam e indexam as revistas nacionais. Os dois títulos seguintes maior em número de publicações possuem acesso aberto: o grande conjunto com as demais revistas possuem circulação regional, entre a região sul e sudeste e dois títulos internacionais são publicados em Portugal, com artigos publicados, portanto, em língua portuguesa.

Por vezes, a internacionalização da ciência não ocorre em determinadas áreas e mesmo em trabalhos acadêmicos, ao usar referencial teórico de autores internacionais pode não ser o método mais adequado, dependendo dos objetivos, do contexto e das variantes da pesquisa. Neste estudo, em particular, os estudos que puderam auxiliar nas análises dos resultados são na maioria publicados no Brasil, uma vez que foi analisada uma comunidade científica brasileira e predominantemente periódicos nacionais. Certas situações ou fenômenos dentro da comunicação científica brasileira são incomuns em outros países como, por exemplo, o elevado número de revistas de acesso aberto e o processo editorial dos periódicos ocorrer dentro das IES, sem a presença do publisher.

Pensando ainda em internacionalização, publicar em idioma português é outro fator que limita o processo. Alguns periódicos, embora possibilitem a publicação em outros idiomas, a língua portuguesa é predominante. Novamente questiona-se: atingirá o público a que se destina? Estas publicações pretendem mesmo se internacionalizar ou o desejo é ser bem avaliada e assim, consequentemente, receber fomento para poder continuar existindo? É preciso fazer uma reflexão se os modelos internacionais podem ser utilizados no Brasil. Certamente é desejável a qualificação da produção científica do país e os modelos internacionais são indiscutivelmente altamente qualificados, mas não sem antes verificar o que pode ser negligenciado neste processo todo, bem como o que realmente pode melhorar.

A produção em periódicos científicos é marcante na pós-graduação da comunidade de docentes da FACED provavelmente não destoa de outras comunidades e áreas do conhecimento. O periódico científico tem sido o veículo de comunicação utilizado por diversas áreas do conhecimento na atualidade, até mesmo aquelas que não possuíam esta tradição. É possível apontar, entre as diversas causas como: o alcance e circulação das revistas dentro da academia, em especial o fornecido pelo acesso aberto e pela Internet; a agilidade e os custos 
menores da publicação, se comparada com livros; e a credibilidade dentre a comunidade científica, uma vez que existe a avaliação por pares.

O aumento da produção em periódicos científicos identificado no período de dados da pesquisa provavelmente se dá em conjunto com o crescimento da Pós-Graduação no país e também pelos requisitos para ingresso e permanência dos docentes nos PPG. A resolução para docentes é de 2013 e para discentes, de 2015. É possível inferir que os próximos anos, incluindo 2014 que já consta na pesquisa, haverá aumento da produção em artigos de alunos de pós-graduação em conjunto com seus orientadores.

Por fim, este estudo só pode ser realizado desta maneira através de coleta de dados em base de dados não tradicionalmente utilizada em estudos métricos. Se os dados fossem coletados de uma base de dados com viés internacional, dificilmente as indagações lançadas durante a análise dos resultados seria possível. É utópico afirmar que uma determinada base de dados represente integralmente uma área do conhecimento, porém o método utilizado neste trabalho foi o mais próximo da realidade dos artigos publicados pelos docentes da FACED durante seu vínculo profissional como professor universitário da UFRGS. As limitações apresentadas nos resultados demostraram fatos importantes, como a falta de diálogo com a teoria e a prática profissional bibliotecária.

A questão norteadora da pesquisa, bem como os objetivos, foram atendidos neste trabalho. É primordial a análise qualitativa desses dados, que poderá ser realizada através de depoimentos desses docentes: a análise de dados, de forma quantitativa, proporcionou a demonstração de um fenômeno sob uma visão, gerado por indicadores.

\section{Referências}

ANDRADE, Rodrigo de Oliveira. Para publicar com critério. Pesquisa FAPESP, São Paulo, v. 244, 2016, p. 96-97. Disponível em: http://revistapesquisa.fapesp.br/2016/06/15/para-publicarcom-criterio/ Acesso em: 28 fev. 2018.

CAFÉ, Lígia; BRÄSCHER, Marisa. Organização da informação e bibliometria. Encontros Bibli: Revista Eletrônica de Biblioteconomia e Ciência da Informação, Florianópolis, v. 13, n. esp., 1응 sem. 2008, p. 54-75.

CARVALHO, Y. M.; MANOEL, E. J. Para além dos indicadores de avaliação da produção intelectual na grande área da saúde. Movimento, Porto Alegre, v. 12, n. 3, p. 193-225, set./dez. $2006 . \quad$ Disponível em: http://www.seer.ufrgs.br/index.php/Movimento/article/view/2915/1551 Acesso em: 15 mar. 2015.

CONSELHO NACIONAL DE DESENVOLVIMENTO CIENTÍFICO E TECNOLÓGICO (CNPQ). Censos: plano tabular. Disponível em: http://lattes.cnpq.br/web/dgp/sobre12 Acesso em: 30 out. 2016. 
COSTA, Ana Ludmila Freire. Publicação e avaliação de periódicos científicos: paradoxos da classificação Qualis em Psicologia. 2006. 213 f. Dissertação (Mestrado em Psicologia) Universidade Federal do Rio Grande do Norte, Natal, 2006. Disponível em: http://repositorio.ufrn.br:8080/jspui/bitstream/123456789/17430/1/AnaLFC.pdf Acesso em 15 ago. 2015

EVANS, James A.; REIMER, Jacob. Open Access and Global Participation in Science. Science, Washington, v. 323, n. 5917, p. 1025, Feb. 2009. Disponível em: http://www.sciencemag.org/cgi/content/full/323/5917/1025 Acesso em: 24 ago. 2015.

FORATTINI, Oswaldo Paulo. A tríade da publicação científica. Revista Saúde Pública, São Paulo, v. 30, n. 1, p. 3-12, fev. 1996. Disponível em: http://www.scielo.br/pdf/rsp/v30n1/5037.pdf Acesso em: 30 set. 2015.

FRIGERI, Mônica; MONTEIRO, Marko Synésio Alves. Qualis Periódicos: indicador da política científica no Brasil? Estudos de Sociologia, Araraquara, v. 19, n. 37, 2015. Disponível em: http://seer.fclar.unesp.br/estudos/article/view/6266/5227 Acesso em: 19 set. 2015.

GIMÉNEZ-TOLEDO, E., Tejada-Artigas, C., \& Mañana-Rodríguez, J. Evaluation of scientific books' publishers in social sciences and humanities: Results of a survey. Research Evaluation, v. 22, n. 1, p. 64-77, 2013. doi:10.1093/reseval/rvs036

GLÄNZEL, Wolfgang. Bibliometrics as a research field: a course on theory and application of bibliometric indicators. [S.L.]: Courses Handout, 2003. Disponível em: https://www.researchgate.net/publication/242406991 Bibliometrics as a research field A course on theory and application of bibliometric indicators

HOOD, W. W; WILSON, C. S. The literature of bibliometrics, scientometrics, and informetrics. Scientometrics, Budapest v. 52, n. 2, p. 291-314, Oct. 2001.

KUHN, Thomas. A estrutura das revoluções científicas. 5. Ed. São Paulo: Perspectiva, 1998.

MEADOWS, Arthur J. A Comunicação Científica. Brasília: Briquet de Lemos, 1999.

MEIS, Leopoldo de; LETA, Jacqueline. O Perfil da Ciência Brasileira. Rio de Janeiro: Editora UFRJ, $1996.103 \mathrm{p}$.

MENEGHINI, Rogério. Pesquisador Desmente Ministro Sobre Produção Científica. Agência FAPESP. Artigo publicado no jornal Folha de São Paulo em 12/5/2009. Disponível em: http://www.fapesp.br/materia/5175 Acesso em: 15 set. 2015.

MENEGHINI, Rogério. Publicação de periódicos nacionais de ciência em países emergentes. Educação em revista, Belo Horizonte, v. 28, n. 2, p. 435-442, Jun. 2012. Disponível em: http://www.scielo.br/pdf/edur/v28n2/a20v28n2.pdf Acesso em: 06 set. 2015.

MUGNAINI, Rogério. Caminhos para adequação da avaliação da produção científica brasileira: impacto nacional versus internacional. 2006. 254 p. Tese (Doutorado em Cultura e Informação) -Universidade de São Paulo, São Paulo, 2006. Disponível em: http://www.teses.usp.br/teses/disponiveis/27/27151/tde-11052007-091052/ Acesso em: 1 jun. 2015. 
NEDERHOF, A. J. Bibliometric monitoring of research performance in the Social Sciences and the Humanities: a review. Scientometrics, Budapest, v. 66, n. 1, p. 81-100, 2006. Disponível em: http://link.springer.com/article/10.1007\%2Fs11192-006-0007-2 Acesso em: 17 set. 2015.

OLIVEIRA, Z. P. et al. O uso do campo MARC 9XX para controle bibliográfico institucional. Ciência da Informação, Brasília, v.33, n.2, dez. 2004. Disponível em: http://revista.ibict.br/ciinf/index.php/ciinf/article/view/105 Acesso em: 21 mar. 2016.

PACKER, Abel L; MENEGHINI, Rogério. Visibilidade da Produção Científica. In: POBLACION, Dinah Aguiar; WITTER, Geraldina Porto; SILVA, José Fernando Modesto da (Org.). Comunicação \& Produção Científica: contexto, indicadores e avaliação. São Paulo: Angellara, 2006.

PIZZANI, Luciana; SILVA, Rosemary Cristina da; HAYASHI, Maria Cristina Piumbato Innocentini. Bases de dados e bibliometria: a presença da Educação Especial na base Medline. Revista Brasileira de Biblioteconomia e Documentação, Nova Série, São Paulo, v. 4, n. 1, p. 68-85, jan./jun. 2008.

SANTOS, Solange Maria dos. Perfil dos periódicos científicos de Ciências Sociais e de Humanidades: mapeamento das características extrínsecas. 2010. 176 f. Dissertação (Mestrado) - Escola de Comunicação e Artes, Pós-graduação em Ciência da Informação, Universidade de São Paulo, São Paulo, 2010.

PRICE, Derek de Solla. O desenvolvimento da ciência: análise histórica, filosófica, sociológica e econômica. Rio de Janeiro: Livros Técnicos e Científicos, 1976. 77p.

SPINAK, Ernesto. Indicadores Cienciométricos. Ciência da Informação, Brasília, v. 27, n. 2., p. 141-148, maio/ago. 1998.2 Disponível em: http://revista.ibict.br/cienciadainformacao/index.php/ciinf/article/view/349/1690 Acesso em: 15 jun. 2015

VALÉRIO, Palmira Mariconi. Espelho da Ciência: avaliação do programa setorial de publicações em ciência e tecnologia da FINEP. Brasília: FINEP/IBICT, 1994.

VANZ, Samile Andrea de Souza; STUMPF, Ida Regina Chittó. Procedimentos e ferramentas aplicados aos estudos bibliométricos. Informação \& Sociedade: Estudos, João Pessoa, v. 20, n. 2, p. 67-75, maio/ago. 2010.2 Disponível em: http://www.ies.ufpb.br/ojs/index.php/ies/article/view/4817/4358 Acesso em: 7maio 2015.

VASCONCELOS, Sonia Maria Ramos de; SORENSON, Martha Meriwether; LETA, Jacqueline. Scientist-friendly Policies for Non-native English-speaking authors: timely and welcome. Brazilian Journal of Medical and Biological Research, Ribeirão Preto, v. 40, n. 6, jun. 2007. Disponível em: http://www.scielo.br/pdf/bjmbr/v40n6/6753.pdf Acesso em: 29 jul. 2015.

VINKLER, Peter. Publication growth in science. In: VINKLER, Peter. The evaluation of research by scientometric indicators. Oxford: Chandos, 2010, cap. 4, p. 23-34.

UNIVERSIDADE FEDERAL DO RIO GRANDE DO SUL. Conselho de Ensino, Pesquisa e Extensão. 2006. Resolução 38/2006, de 6 de setembro de 2006. Disponível em: http://www.ufrgs.br/cepe/legislacao/resolucao-no-38-2006-de-06-09-2006 Acesso em: 17 out. 2016. 
UNIVERSIDADE FEDERAL DO RIO GRANDE DO SUL. Conselho Universitário. 2001. Decisão 118/2001, de 17 de agosto de 2001. Disponível em: http://www.ufrgs.br/consun/legislacao/documentos/decisao-no-118-2001 Acesso em: $11 \mathrm{dez}$. 2016.

UNIVERSIDADE FEDERAL DO RIO GRANDE DO SUL. Faculdade de Educação UFRGS. 2015. Disponível em: http://www.ufrgs.br/faced/ Acesso em: 22 jul. 2015.

ZANOTTO, Sonia Regina et. al. Análise de citações utilizando o Google acadêmico: estudo com os periódicos Intexto e Em Questão. In: Hayashi, Maria Cristina Piumbato Innocentini; Mugnaini, Rogério; Hayashi, Carlos Roberto Massao (Org.). Bibliometria e Cientometria: metodologias e aplicações. São Carlos: Pedro \& João, 2013. p. 171-181 